\title{
PENERAPAN METODE MULTI ATTRIBUTE UTILITY THEORY (MAUT) DALAM PEMETAAN TINGKAT DAMPAK BENCANA BANJIR DI KABUPATEN BANTUL
}

\author{
Afif Irfan Abdurrahman (1), Bambang Yuwono (2), Yuli Fauziah ${ }^{(3)}$ \\ Program Studi Teknik Informatika Fakultas Teknik Industri UPN “Veteran” Yogyakarta \\ Jln. Babarsari 2, Tambak Bayan, Yogyakarta \\ e-mail : afifirfan098@gmail.com, bambangy@gmail.com, yuli.if@gmail.com
}

\begin{abstract}
Flood disaster is a dangerous disaster, an event that occurs due to overflow of water resulting in submerged land is called a flood disaster. Almost every year Bantul Regency is affected by floods due to high rainfall. The flood disaster that struck in Bantul Regency made the Bantul District Disaster Management Agency (BPBD) difficult to handle so that it needed a mapping of the level of the impact of the flood disaster to minimize the occurrence of floods and provide information to the public.

This study will create a system to map the level of impact of floods in Bantul Regency with a decision support method namely Multi Attribute Utility Theory (MAUT). The MAUT method stage in determining the level of impact of flood disasters through the process of normalization and matrix multiplication. The method helps in determining the areas affected by floods, by managing the Indonesian Disaster Information Data (DIBI). The data managed is data on criteria for the death toll, lost victims, damage to houses, damage to public facilities, and damage to roads. Each criteria data has a value that can be used to determine the level of impact of a flood disaster. The stages for determining the level of impact of a disaster require a weighting calculation process. The results of the weighting process display the scoring value which has a value of $1=$ low, $2=$ moderate, $3=$ high. To assist in determining the affected areas using the matrix normalization and multiplication process the process is the application of the Multi Attribute Utility Theory (MAUT) method.

This study resulted in a mapping of the level of impact displayed on google maps. The map view shows the affected area points and the level of impact of the flood disaster in Bantul Regency. The mapping produced from the DIBI data in 2017 produced the highest affected area in the Imogiri sub-district. The results of testing the data can be concluded that the results of this study have an accuracy rate of $95 \%$ when compared with the results of the mapping previously carried out by BPBD Bantul Regency. The difference in the level of accuracy is because the criteria data used are not the same as the criteria data used by BPBD in Bantul Regency so that the accuracy rate is $95 \%$.
\end{abstract}

Keywords: Flood, Multi Attribute Utility Theory (MAUT), Waterfall, google maps.

Bencana banjir merupakan bencana berbahaya, peristiwa yang terjadi akibat luapan air sehingga mengakibatkan terendamnya daratan disebut dengan bencana banjir. Hampir setiap tahun Kabupaten Bantul terkena bencana banjir dikarenakan tinggiya curah hujan. Bencana banjir yang melanda di Kabupaten Bantul membuat Badan Penanggulangan Bencana Daerah (BPBD) Kabupaten Bantul kesulitan dalam menanganinya sehingga membutuhkan pemetaan tingkat dampak bencana banjir untuk meminimalisir terjadinya bencana banjir dan memberikan informasi kepada masyarakat.

Penelitian ini akan membuat sistem untuk memetakan tingkat dampak bencana banjir di Kabupaten Bantul dengan metode pendukung keputusan yaitu Multi Attribute Utility Theory (MAUT). Tahapan metode MAUT dalam menentukan tingkat dampak bencana banjir melalui proses normalisasi dan perkalian matriks. Metode tersebut membantu dalam menentukan daerah yang terdampak bencana banjir, dengan mengelola Data Informasi Bencana Indonesia (DIBI). Data yang dikelola adalah data kriteria korban meninggal, korban hilang, kerusakan rumah, kerusakan fasilitas umum, dan kerusakan jalan. Setiap data kriteria memiliki nilai yang dapat digunakan untuk menentukan tingkat dampak bencana banjir. Tahapan untuk menentukan tingkat dampak bencana memerlukan proses perhitungan pembobotan. Hasil dari proses pembobotan menampilkan nilai skoring yang memiliki nilai 1 = rendah, 2 = sedang, 3 = tinggi. Untuk membantu dalam menentukan daerah yang terdampak menggunakan proses normalisasi dan perkalian matriks proses tersebut merupakan penerapan dari metode Multi Attribute Utility Theory (MAUT).

Penelitian ini menghasilkan pemetaan tingkat dampak yang ditampilkan pada google maps. Tampilan peta menampilkan titik wilayah terdampak serta tingkat dampak bencana banjir di Kabupaten Bantul. Pemetaan yang dihasilkan dari data DIBI di tahun 2017 menghasilkan wilayah yang terkena dampak paling tinggi diwilayah kecamatan imogiri. Hasil pengujian data dapat diambil kesimpulan bahwa hasil penelitian ini memiliki tingkat keakuratan 95\% jika dibandingkan dengan hasil pemetaan yang sebelumnya dilakukan oleh BPBD Kabupaten Bantul. Perbedaan tingkat keakuratan ini disebabkan karena data kriteria yang digunakan tidak sama dengan data kriteria yang digunakan BPBD Kabupaten Bantul sehingga untuk tingkat keakuratannya sebesar 95\%.

Kata Kunci : Banjir, Multi Attribute Utility Theory (MAUT), Waterfall, google maps. 


\section{PENDAHULUAN}

Banjir merupakan sebuah peristiwa yang terjadi akibat luapan air yang mengakibatkan terendamnya daratan. Luapan air disebabkan karena meningkatnya curah hujan sehingga menyebabkan meningkatnya volume air pada sungai dan danau. Faktor penyebab terjadinya banjir dapat diklasifikasikan dalam dua kategori yaitu banjir alami dan banjir oleh tindakan manusia. Banjir alami dipengaruhi oleh curah hujan, fisiografi, erosi dan kapasitas sungai. Sedangkan Banjir oleh tindakan manusia disebabkan karena ulah manusia yang menyebabkan perubahan - perubahan lingkungan seperti perubahan kondisi Daerah Aliran Sungai (DAS), kawasan pemukiman di sekitar bantaran, rusaknya drainase lahan, kerusakan bangunan pengendali banjir, dan perencanaan sistem pengendali banjir yang tidak tepat (Kodoatie, \& Sugiyanto , 2002).

Kabupaten Bantul terletak di sebelah Selatan Provinsi Daerah Istimewa Yogyakarta. Luas wilayah Kabupaten Bantul 506,85 Km² (15,90 5 dari Luas wilayah Propinsi DIY) dengan topografi sebagai dataran rendah $140 \%$ dan lebih dari separonya $(60 \%)$ daerah perbukitan yang kurang subur. Kabupaten Bantul memiliki pembagian administratif yaitu 17 kecamatan, 75 kelurahan dan 933 Dusun. Kabupaten Bantul dialiri beberapa sungai besar seperti Sungai Oyo, Sungai Opak, Sungai Code, Sungai Winongo, Sungai Bedog, dan Sungai Progo.

Pada bulan November 2017 Kabupaten Bantul mengalami bencana banjir yang diakibatkan karena tingginya curah hujan yang terjadi di Kota Yogyakarta. Curah hujan yang tinggi mengakibatkan meluapnya beberapa sungai yang mengelilingi Kabupaten Bantul. Banyak masyarakat Kabupaten Bantul yang mengalami kerugian materi dan trauma. Selain bencana banjir tersebut banyak merugikan masyarakat, bencana banjir telah merusak beberapa fasilitas umum yang ada di Kabupaten Bantul seperti jembatan roboh, jalan rusak dan padamnya arus listrik.

Tetapi dalam bencana tersebut masyarakat telah dibantu oleh Badan Penanggulangan Bencana Daerah (BPBD) Kabupaten Bantul dan para relawan. Bantuan yang diberikan BPBD Kabupaten Bantul berupa mendirikan posko pengungsian, memberi sembako, dan membersihkan rumah serta fasilitas umum dari lumpur. Selain itu dari BPBD juga melakukan pendataan untuk laporan bencana yang biasa disebut Data Informasi Bencana Indonesia (DIBI) yang dilakukan oleh bidang Pusat Pengendalian Operasi Penanggulangan Bencana (PUSDALOPS). Dari pendataan yang dilakukan oleh PUSDALOPS, data yang ada dapat dijadikan sumber informasi dalam menentukan daerah yang mengalami tingkat dampak bencana banjir di Kabupaten Bantul. Sehingga dengan data tersebut dapat menentukan daerah mana yang harus diperhatikan oleh pemerintah Kabupaten Bantul agar meminimalisir bencana banjir.

Dengan kejadian bencana banjir di bulan November 2017 yang lalu, bencana banjir merupakan bencana alam yang berbahaya. Dikarenakan dengan bencana banjir tersebut sangat merugikan banyak orang selain merugikan juga menimbulkan korban. Maka dibutuhkan sebuah pemahaman yang dapat dijadikan masukan bagi pemerintah daerah khususnya pemerintah Kabupaten Bantul untuk lebih memberi perhatian khusus pada wilayah yang menjadi daerah rawan bencana banjir. Untuk membantu kinerja pemerintah daerah dalam melakukan perhatian khusus pada daerah yang rawan bencana banjir maka perlu dilakukan sebuah pemetaan tingkat dampak bencana banjir khusunya di Kabupaten Bantul. Pemetaan ini dapat dipetakan dengan Sistem Informasi Geografis.

Dalam menetukan daerah yang memiliki tingkat dampak bencana banjir, memiliki beberapa kriteria yang menentukan daerah tersebut termasuk daerah terdampak bencana banjir atau tidak. Dalam menentukan permasalahan tingkat dampak bencana banjir, dalam penelitian ini digunakan sebuah metode sistem pendukung keputusan yaitu metode Multi Attribute Utility Theory (MAUT) untuk membantu dalam pendukung keputusan suatu permasalahan. Menurut Schaefer, Multi Attribute Utility Theory (MAUT) merupakan suatu skema yang evaluasi akhir, $v(x)$, dari suatu objek $x$ didefinisikan sebagai bobot yang dijumlahkan dengan suatu nilai yang relevan terhadap nilai dimensinya.

Sebelumnya terdapat sebuah penelitian dengan judul "Analisa dan Perancangan Sistem Pendukung Keputusan Untuk Penerimaan Karyawan PT. Dos Ni Roha Jambi Menggunakan Metode MAUT (Multi Attribute Utility Theory) " yang dilakukan oleh (Muhammad Hidayat \& Pareza AlamJusia ,2018). Pada penelitian tersebut dapat disimpulkan bahwa metode Multi Attribute Utility Theory (MAUT) sangat membantu perusahhan dalam menyeleksi karyawan baru. Perancangan sistem pendukung keputusan pemilihan karyawan dengan metode MAUT ini menghasilkan perhitungan yang jelas sebagai rekomendasi untuk pengambil 
keputusan sehingga perusahaan bisa mendapatkan sumber daya manusia yang berkualitas untuk mencapai target perusahaan.

Alasan menggunakan metode MAUT karena dalam penelitian sebelumnya metode MAUT digunakan untuk mengelola data yang bersifat data kuantitatif yaitu data angka, selain itu data yang diolah berjenis data primer yaitu data yang dikumpulkan perseorangan, organisasi atau instansi dengan cara didapat langsung dalam studi yang berkaitan dengan cara interview atau observasi. Dilihat dari penelitian sebelumnya data yang diolah memiliki kesamaan sifat dan jenisnya, sehingga dalam penelitian ini digunakan metode MAUT untuk metode pendukung dalam menentukan tingkat dampak bencana banjir, karena dirasa metode tersebut sangat cocok untuk diterapkan dalam proses perhitungannya dibandingkan dengan metode yang lainnya.

Dengan menggunakan metode ini pada hasil akhirnya akan memunculkan hasil urutan peringkat dimana akan muncul hasil nilai terbesar sampai nilai terkecil sehingga dapat diketahui daerah mana yang memiliki tingkat resiko rawan bencana banjir. Sehingga dapat mengambil keputusan dengan efektif atas persoalan yang kompleks dengan menyederhanakan dan mempercepat proses pengambilan keputusan. Dalam penelitian ini membuat sebuah media sistem informasi geografis yang menampilkan informasi daerah yang terdampak bencana banjir sehingga dapat mengetahui daerah yang rawan bencana banjir khususnya di Kabupaten Bantul dengan menggunakan teknologi berbasis web. Hal tersebut diharapkan dapat membantu pemerintahan Kabupaten Bantul dan Badan Penanggulangan Bencana Daerah (BPBD) Kabupaten Bantul dalam melakukan pemantauan daerah rawan bencana banjir agar meminimalisir terjadinya bencana banjir

\section{Metode Penelitian}

Metodologi penelitian yang digunakan adalah metode kuantitatif. Metode kuantitatif sendiri lebih sistematis, terencana, terstruktur dan jelas dari awal hingga akhir penelitian. Menurut Sugiyono (2012), metode kuantitatif dapat diartikan sebagai metode penelitian yang berlandaskan pada filsafat positifisme, digunakan untuk meneliti pada populasi atau sampel tertentu. Sampel yang digunakan dalam penelitian ini menggunakan Data Informasi Bencana Indonesia (DIBI). Metode yang diterapkan untuk pengembangan sistem dalam penelitian ini adalah metode waterfall. Metode Pengembangan sistem (waterfall) memiliki tahap-tahap sebagai berikut yaitu analisis kebutuhan, desain sistem, Implementasi dan pengujian unit, pengujian sistem, perawatan (maintance).

\subsection{Metodologi Pengumpulan Data}

\section{a. Studi Pustaka}

Studi Pustaka merupakan proses pengumpulan buku atau jurnal penelitian sebagai refrensi yang memiliki tujuan untuk memperkuat materi pembahasan dalam penelitian yang dilakukan dan mempelajari dasar - dasar rumus yang diperlukan.

b. Observasi

Observasi merupakan sebuah proses pencatatan atau pengamatan untuk sebuah fenomena untuk mendapatkan informasi yang dibutuhkan dalam melakukan penelitian. Penelitian ini melakukan observasi di Badan penanggulangan Bencana Daerah (BPBD) Kabupaten Bantul karena instansi tersebut yang berhubungan dengan penelitian tentang bencana banjir khususnya di Kabupaten Bantul.

c. Wawancara

Wawancara dilakukan dengan staff bidang Pusat Pengendalian Operasi Penanggulangan Bencana (PUSDALOPS) yang ada di BPBD Kabupaten Bantul. Informasi yang didapatkan seperti proses perhitungan skoring serta beberapa kriteria yang dibutuhkan dalam penentuan tingkat dampak bencana banjir di kawasan Kabupaten Bantul.

\subsection{Metodologi Pengembangan Sistem}

Metodologi pengembangan sistem yang digunakan dalam penelitian ini menggunakan metode pengembangan sistem waterfall. Metode waterfall adalah metode pengembangan software yang menyediakan pendekatan alur hidup perangkat lunak yang teratur serta mempunyai tahapan-tahapan yang jelas. Tahapan dari metode ini dimulai dari analisis kebutuhan sistem, desain sistem, implementasi sistem, pengujian sistem dan pemeliharaan 
sistem (Imam Rofi'i, Hendrawan, Pareza Alam Jusia, 2015). Metode pengembangan sistem waterfall dapat digambarkan seperti dibawah ini :

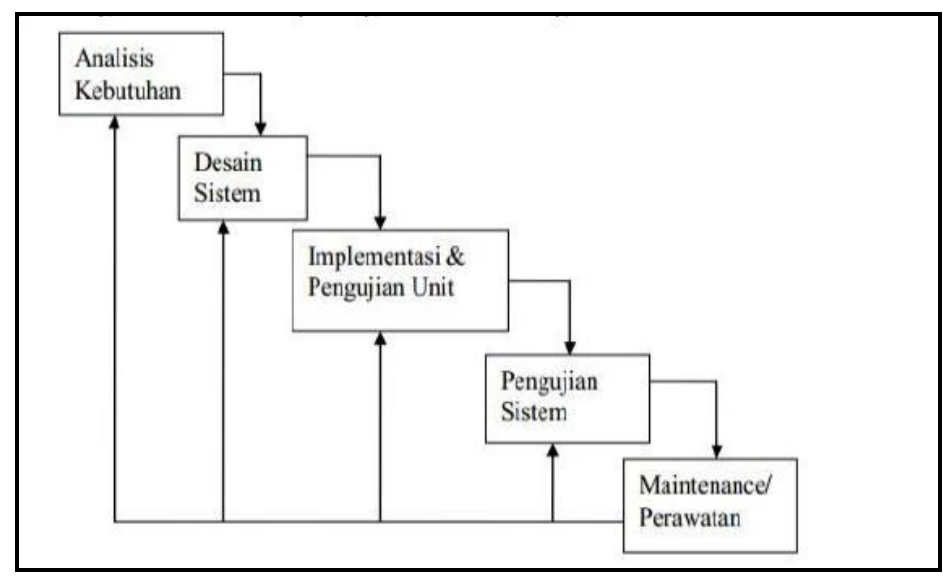

Gambar 1 Model Metode Waterfall

Tahapan metode waterfall yang pertama analisis kebutuhan proses ini merupakan tahapan untuk mendalami konsep sebuah sistem yang akan dibuat dengan tujuan untuk mendefinisikan sistem berjalan yang berguna sebagai landasan bagi sistem baru yang akan dirancang nantinya. Kedua desain sistem merupakan proses menterjemahkan tahap analisis yang dilakukan sebelumnya ke dalam bentuk rancangan sebelum pembuatan program berupa perancangan antarmuka. Ketiga implementasi dan pengujian unit proses ini merupakan implementasidari perancangan atau desain sistem ke situasi nyata. Keempat pengujian sistem proses ini melakukan pengujian program (coding) yang telah dibuat untuk di implementasikan ke aplikasi yang telah dirancang. Yang terakhir perawatan (maintenance) tahap ini merupakan tahap dan perawatan pada saat pengoperasian sistem.

\subsection{Arsitektur Sistem}

Perancangan arsitektur sistem mengambarkan sebuah proses berjalannnya sebuah sistem. Arsitektur sistem ini terdiri dari admin dan user. Dimana fungsi admin dan user memiliki perbedaan dalam mengakses sistem. Arsitektur sistem menggambarkan terdapat tiga entitas yang mengakses sistem yaitu admin, pusdalops dan user public. Dari ketiga entitas tersebut terhubung dengan sistem. Sistem terhubung dengan database untuk mengelola atau menampilkan data. Pada saat mengakses sistem untuk menampilkan peta harus terhubung dengan internet agar dapat terhubung dengan google maps. Tampilannya dapat dilihat pada Gambar 2.

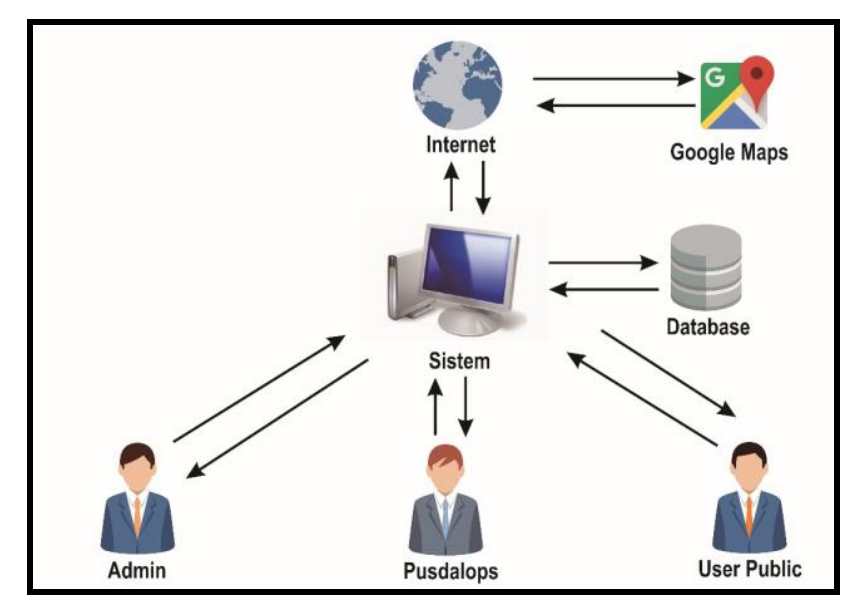

Gambar 2 Perancangan Arsitektur Sistem 


\subsection{Perancangan Proses}

Berikut ini merupakan tahap dalam perancangan proses berupa Flowchart dalam proses perhitungan pembobotan, normalisasi dan perkalian matriks.

a. Flowchart Pembobotan

Flowchart pembobotan merupakan alur dari proses perhitungan pembobotan kriteria.

Tampilannya dapat dilihat pada Gambar 3.

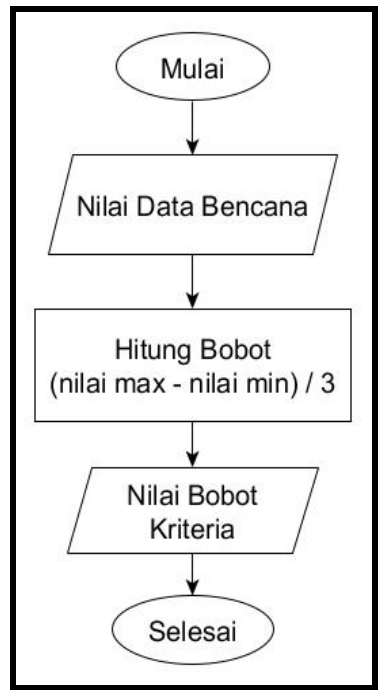

Gambar 3 Flowchart Pembobotan

b. Flowchart Normalisasi Dan Matriks

Flowchart normalisasi dan matriks merupakan proses perhitungan dari penerapan metode Multi Attribute Utility Theory (MAUT). Flowchart normalisasi dan matriks dapat dilihat pada Gambar 4.

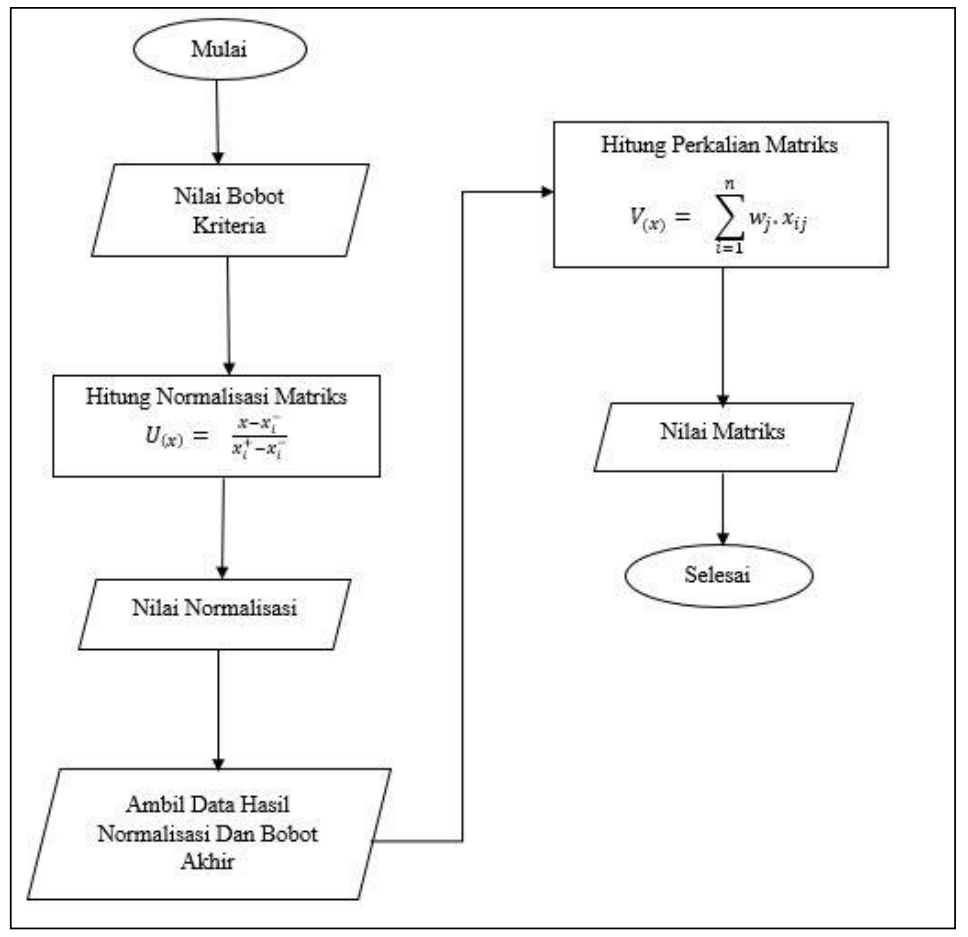

Gambar 4 Flowchart Normalisasi Dan Matriks 


\section{Hasil dan Pembahasan}

Hasil dan pembahasan akan menjelaskan penerapan penggunaan metode Multi Attribute Utility Theory (MAUT), hasil pengujian sistem dan pengujian data dari sistem pemetaan tingkat dampak bencana banjir di Kabupaten Bantul.

\subsection{Multi Attribute Utility Theory (MAUT)}

Menurut Schaefer, Multi Attribute Utility Theory (MAUT) merupakan suatu skema yang evaluasi akhir, $v(x)$, dari suatu objek $x$ didefinisikan sebagai bobot yang dijumlahkan dengan suatu nilai yang relevan terhadap nilai dimensinya. Ungkapan yang biasa digunakan untuk menyebutnya adalah nilai utilitas MAUT digunakan untuk merubah dari beberapa kepentingan kedalam nilai numerik dengan skala 0-1 dengan 0 mewakili pilihan terburuk dan 1 terbaik. Hal ini memungkinkan perbandingan langsung yang beragam ukuran. Hasil akhirnya adalah urutan peringkat dari evaluasi alternatif yang menggambarkan pilihan dari para pembuat keputusan. Untuk perhitungannya dapat dirumuskan sebagai berikut:

$$
V_{(x)}=\sum_{i=1}^{n} w_{j}, x_{i j}
$$

Sedangkan untuk rumus perhitungan normalisasi matrik sebagai berikut :

$$
U_{(x)}=\frac{x-x_{i}^{-}}{x_{i}^{+}-x_{i}^{-}}
$$

Keterangan:

$\mathrm{U}(\mathrm{x}) \quad=$ Normalisasi bobot alternative

$\mathrm{x}=$ Bobot alternative

$x_{i}^{-}=$Bobot terburuk (minimum) dari kriteria ke-x

$x_{i}^{+} \quad=$ Bobot terbaik (maximum)

\subsection{Implementasi Perhitungan Metode Multi Attribute Utility Theory (MAUT)}

Pada pemetaan tingkat dampak bencana banjir untuk menentukan tingkat dampaknya dilakukan perhitungan pembobotan. Sedangkan untuk penerapan metode Multi Attribute Utility Theory (MAUT) terdapat proses perhitungan normalisasi dan perkalian matriks sebelum menentukan rangking. Berikut adalah sampel perhitungan pembobotan, normalisasi dan perkalian matriks dari penerapan metode Multi Attribute Utility Theory (MAUT) :

\begin{tabular}{|c|c|c|c|c|c|c|c|c|}
\hline \multirow{3}{*}{ No } & \multirow{3}{*}{ Kecamatan } & \multicolumn{7}{|c|}{ Kriteria } \\
\hline & & \multirow{2}{*}{$\begin{array}{c}\text { Korban } \\
\text { Meninggal }\end{array}$} & \multirow{2}{*}{$\begin{array}{c}\text { Korban } \\
\text { Hilang }\end{array}$} & \multicolumn{3}{|c|}{ Kerusakan Rumah } & \multirow{2}{*}{$\begin{array}{c}\text { Kerusakan } \\
\text { Fasilitas } \\
\text { Umum }\end{array}$} & \multirow{2}{*}{$\begin{array}{c}\text { Kerusakan } \\
\text { Jalan }\end{array}$} \\
\hline & & & & Berat & Sedang & Ringan & & \\
\hline 1 & Banguntapan & 0 & 0 & 1 & 0 & 1 & 8 & 0,045 \\
\hline 2 & Bantul & 0 & 0 & 0 & 0 & 0 & 15 & 0,04 \\
\hline 3 & Imogiri & 0 & 0 & 8 & 28 & 51 & 11 & 0,245 \\
\hline 4 & Jetis & 0 & 0 & 0 & 0 & 4 & 8 & 0,06 \\
\hline 5 & Kasihan & 0 & 0 & 0 & 0 & 3 & 0 & 0 \\
\hline 6 & Kretek & 0 & 0 & 2 & 0 & 3 & 8 & 0,05 \\
\hline 7 & Pajangan & 0 & 0 & $\frac{5}{1}$ & 0 & 2 & 3 & 0,3 \\
\hline 8 & Pandak & 0 & 0 & 1 & 0 & 0 & 3 & 0 \\
\hline 9 & Pundong & 0 & 0 & 2 & 1 & 1 & 8 & 0,5 \\
\hline 10 & Pleret & 0 & 0 & 0 & 0 & 3 & 3 & 0 \\
\hline
\end{tabular}

Tabel 1 Data Bencana Kecamatan

Diatas merupakan sampel data bencana kecamatan, dimana data bencana tersebut yang akan digunakan untuk melakukan perhitungan pembobotan. Untuk mencari nilai bobot rumusnya sebagai berikut : 
Bobot $=($ nilai $\max -$ nilai $\min ) / 3$

Perhitungan Pembobotan :

a. Kriteria Korban Meninggal
$(0-0) / 3$
$=0$

b. Kriteria Korban Hilang
$(0-0) / 3$
$=0$

c. Kriteria Kerusakan Rumah Berat
$(8-0) / 3$
$=2,66$
$1-2,66$
$=1$ (Rendah)
$2,67-5,33$
$=2$ (Sedang)
$5,34-8$
$=3$ (Tinggi)

d. Kriteria Kerusakan Rumah Sedang
$(28-0) / 3$
$=9,33$
$1-9,33$
$=1$ (Rendah)
$9,34-18,67$
$=2$ (Sedang)
$18,68-28,01$
$=3$ (Tinggi)

e. Kriteria Kerusakan Rumah Ringan
$(51-0) / 3$
$=17$
$1-17$
$=1$ (Rendah)
$18-35$
$=2$ (Sedang)
$36-53$
$=3$ (Tinggi)

f. Kriteria Kerusakan Fasilitas Umum
$(15-0) / 3=5$
$1-5$
$=1$ (Rendah)
$6-11$
$=2$ (Sedang)
$12-17$
$=3$ (Tinggi)

g. Kriteria Kerusakan Jalan
$(0,5-0) / 3$
$=0,167$
$0,025-0,167$
$=1$ (Rendah)
$0,168-0,335$
$=2$ (Sedang)
$0,336-0,503$
$=3$ (Tinggi)

Perhitungan diatas menghasilkan nilai bobot perkriteria, hasil nilai pembobotan dapat dilihat pada Tabel 2a dan Tabel 2b.

Tabel 2a Pembobotan Kriteria

\begin{tabular}{|c|c|c|c|c|c|c|c|c|}
\hline \multirow{3}{*}{ No } & \multirow{3}{*}{ Kecamatan } & \multicolumn{7}{|c|}{ Kriteria } \\
\hline & & \multirow{2}{*}{$\begin{array}{c}\text { Korban } \\
\text { Meninggal }\end{array}$} & \multirow{2}{*}{$\begin{array}{c}\text { Korban } \\
\text { Hilang }\end{array}$} & \multicolumn{3}{|c|}{ Kerusakan Rumah } & \multirow{2}{*}{$\begin{array}{c}\text { Kerusakan } \\
\text { Fasilitas } \\
\text { Umum }\end{array}$} & \multirow{2}{*}{$\begin{array}{c}\text { Kerusakan } \\
\text { Jalan }\end{array}$} \\
\hline & & & & Berat & Sedang & Ringan & & \\
\hline 1 & Banguntapan & 0 & 0 & 1 & 0 & 1 & 2 & 1 \\
\hline 2 & Bantul & 0 & 0 & 0 & 0 & 0 & 3 & 1 \\
\hline 3 & Imogiri & 0 & 0 & 3 & 3 & 3 & 2 & 2 \\
\hline 4 & Jetis & 0 & 0 & 0 & 0 & 1 & 2 & 1 \\
\hline 5 & Kasihan & 0 & 0 & 0 & 0 & 1 & 0 & 0 \\
\hline 6 & Kretek & 0 & 0 & 1 & 0 & 1 & 2 & 1 \\
\hline 7 & Pajangan & 0 & 0 & 1 & 0 & 1 & 1 & 2 \\
\hline 8 & Pandak & 0 & 0 & 1 & 0 & 0 & 1 & 0 \\
\hline 9 & Pundong & 0 & 0 & 1 & 1 & 1 & 2 & 3 \\
\hline 10 & Pleret & 0 & 0 & 0 & 0 & 1 & 1 & 0 \\
\hline \multicolumn{2}{|c|}{$\begin{array}{c}\text { Jumlah Bobot } \\
\text { Kriteria }\end{array}$} & 0 & 0 & 8 & 4 & 10 & 16 & 11 \\
\hline \multicolumn{2}{|c|}{$\begin{array}{c}\text { Bobot Akhir } \\
\text { Kriteria }\end{array}$} & 0 & 0 & 2 & 1 & 2 & 3 & 3 \\
\hline
\end{tabular}


Tabel 2b Hasil Pembobotan Kriteria

\begin{tabular}{|c|c|c|c|}
\hline Kecamatan & Jumlah Bobot & Skoring & Dampak \\
\hline Banguntapan & 5 & 2 & Sedang \\
\hline Bantul & 4 & 1 & Rendah \\
\hline Imogiri & 13 & 3 & Tinggi \\
\hline Jetis & 4 & 1 & Rendah \\
\hline Kasihan & 1 & 1 & Rendah \\
\hline Kretek & 5 & 2 & Sedang \\
\hline Pajangan & 5 & 2 & Sedang \\
\hline Pandak & 2 & 1 & Rendah \\
\hline Pundong & 8 & 2 & Sedang \\
\hline Pleret & 2 & 1 & Rendah \\
\hline
\end{tabular}

Setelah mendapat nilai bobot selanjutnya melakukan proses perhitungan normalisasi. Perhitungan normalisasi dilakukan perkecamatan sesuai dengan data bencana. Sampel perhitungan normalisasi sebagai berikut :

Hitung Normalisasi Matriks $U_{(x)}=\frac{x-x_{\bar{i}}^{-}}{x_{i}^{+}-x_{i}^{-}}$

Keterangan :

$x=$ Nilai Bobot Kriteria

$\mathrm{x}_{\mathrm{i}^{-}}=$Nilai Bobot Kriteria Terendah

$\mathrm{xi}^{+}=$Nilai Bobot Kriteria Tertinggi

a. Kecamatan Banguntapan
i. Kriteria Korban Meninggal
$(0-0) /(0-0)=0$
ii. Kriteria Korban Hilang
$(0-0) /(0-0)=0$
iii. Kriteria Kerusakan Rumah Berat
$(1-0) /(3-0)=0,33$
iv. Kriteria Kerusakan Rumah Sedang $(0-0) /(3-0)=0$
v. Kriteria Kerusakan Rumah Ringan $(0-0) /(3-0)=0$
vi. Kriteria Kerusakan Fasilitas Umum $(2-0) /(3-0)=0,67$

vii. Kriteria Kerusakan Jalan $(1-0) /(3-0)=0,33$

b. Kecamatan Bantul
i. Kriteria Korban Meninggal
$(0-0) /(0-0)=0$
ii. Kriteria Korban Hilang $(0-0) /(0-0)=0$
iii. Kriteria Kerusakan Rumah Berat $(0-0) /(3-0)=0$
iv. Kriteria Kerusakan Rumah Sedang $(0-0) /(3-0)=0$
v. Kriteria Kerusakan Rumah Ringan $(0-0) /(3-0)=0$
vi. Kriteria Kerusakan Fasilitas Umum $(3-0) /(3-0)=1$
vii. Kriteria Kerusakan Jalan $(1-0) /(3-0)=0,33$

c. Kecamatan Imogiri
i. Kriteria Korban Meninggal $(0-0) /(0-0)=0$ 
ii. Kriteria Korban Hilang

$(0-0) /(0-0)=0$

iii. Kriteria Kerusakan Rumah Berat

$(3-0) /(3-0)=1$

iv. Kriteria Kerusakan Rumah Sedang

$(3-0) /(3-0)=1$

v. Kriteria Kerusakan Rumah Ringan

$(3-0) /(3-0)=1$

vi. Kriteria Kerusakan Fasilitas Umum

$(2-0) /(3-0)=0,67$

vii. Kriteria Kerusakan Jalan

$(2-0) /(3-0)=0,67$

Tabel 3 Hasil Perhitungan Normalisasi

\begin{tabular}{|c|c|c|c|c|c|c|c|c|}
\hline \multirow{3}{*}{ No } & \multirow{3}{*}{ Kecamatan } & \multicolumn{7}{|c|}{ Kriteria } \\
\hline & & \multirow{2}{*}{$\begin{array}{c}\text { Korban } \\
\text { Meninggal }\end{array}$} & \multirow{2}{*}{$\begin{array}{c}\text { Korban } \\
\text { Hilang }\end{array}$} & \multicolumn{3}{|c|}{ Kerusakan Rumah } & \multirow{2}{*}{$\begin{array}{c}\text { Kerusakan } \\
\text { Fasilitas } \\
\text { Umum }\end{array}$} & \multirow{2}{*}{$\begin{array}{c}\text { Kerusakan } \\
\text { Jalan }\end{array}$} \\
\hline & & & & Berat & Sedang & Ringan & & \\
\hline 1 & Banguntapan & 0 & 0 & 0,33 & 0 & 0,33 & 0,67 & 0,33 \\
\hline 2 & Bantul & 0 & 0 & 0 & 0 & 0 & 1 & 0,33 \\
\hline 3 & Imogiri & 0 & 0 & 1 & 1 & 1 & 0,67 & 0,67 \\
\hline 4 & Jetis & 0 & 0 & 0 & 0 & 0,33 & 0,67 & 0,33 \\
\hline 5 & Kasihan & 0 & 0 & 0 & 0 & 0,33 & 0 & 0 \\
\hline 6 & Kretek & 0 & 0 & 0,33 & 0 & 0,33 & 0,67 & 0,33 \\
\hline 7 & Pajangan & 0 & 0 & 0,33 & 0 & 0,33 & 0,33 & 0,67 \\
\hline 8 & Pandak & 0 & 0 & 0,33 & 0 & 0 & 0,33 & 0 \\
\hline 9 & Pundong & 0 & 0 & 0,33 & 0,33 & 0,33 & 0,67 & 1 \\
\hline 10 & Pleret & 0 & 0 & 0 & 0 & 0,33 & 0,33 & 0 \\
\hline
\end{tabular}

Tabel diatas hasil dari perhitungan normalisasi, perhitungan tahap terakhir untuk menentukan rangking adalah perhitungan perkalian matriks sebagai berikut :

Hitung Perkalian Matriks $V_{(x)}=\sum_{i=1}^{n} w_{i} \cdot x_{i \bar{i}}$

Nilai bobot akhir $=0,0,2,1,2,3,3$

Keterangan :

$W j=$ nilai bobot akhir

$X i j=$ nilai normalisasi

a. Kecamatan Banguntapan

$(0.0)+(0.0)+(2.0,33)+(1.0)+(2.0,33)+(3.0,67)+(3.0,33)=4,32$

b. Kecamatan Bantul

$(0.0)+(0.0)+(2.0)+(1.0)+(2.0)+(3.1)+(3.0,33)=3,99$

c. Kecamatan Imogiri

$(0.0)+(0.0)+(2.1)+(1.1)+(2.1)+(3.0,67)+(3.0,67)=9,02$

d. Kecamatan Jetis

$(0.0)+(0.0)+(2.0)+(1.0)+(2.0,33)+(3.0,67)+(3.0,33)=3,66$

e. Kecamatan Kasihan

$(0.0)+(0.0)+(2.0)+(1.0)+(2.0,33)+(3.0)+(3.0)=0,66$

Tabel 4 Hasil Perkalian Matriks

\begin{tabular}{|c|c|c|}
\hline No & Kecamatan & Nilai Matriks \\
\hline 1 & Banguntapan & 4,32 \\
\hline 2 & Bantul & 3,99 \\
\hline 3 & Imogiri & 9,02 \\
\hline
\end{tabular}




\begin{tabular}{|c|c|c|}
\hline No & Kecamatan & Nilai Matriks \\
\hline 4 & Jetis & 3,66 \\
\hline 5 & Kasihan & 0,66 \\
\hline 6 & Kretek & 4,32 \\
\hline 7 & Pajangan & 4,32 \\
\hline 8 & Pandak & 1,65 \\
\hline 9 & Pundong & 6,66 \\
\hline 10 & Pleret & 1,65 \\
\hline
\end{tabular}

Dari hasil perkalian matriks dapat dirangkingkan dari nilai yang paling tinggi sampai paling rendah untuk mengetahui tingkat dampak bencana. Peringkat rangking dapat dilihat pada Tabel 5.

Tabel 5 Rangking Tingkat Dampak Bencana

\begin{tabular}{|c|c|c|c|}
\hline Rangking & Kecamatan & Nilai Matriks & Dampak \\
\hline 1 & Imogiri & 9,02 & Tinggi \\
\hline 2 & Pundong & 6,66 & Sedang \\
\hline 3 & Banguntapan & 4,32 & Sedang \\
\hline 4 & Kretek & 4,32 & Sedang \\
\hline 5 & Pajangan & 4,32 & Sedang \\
\hline 6 & Bantul & 3,99 & Rendah \\
\hline 7 & Jetis & 3,66 & Rendah \\
\hline 8 & Pandak & 1,65 & Rendah \\
\hline 9 & Pleret & 1,65 & Rendah \\
\hline 10 & Kasihan & 0,66 & Rendah \\
\hline
\end{tabular}

\subsection{Tampilan Peta Terdampak}

Peta terdampak menampilkan tampilan peta google maps dimana tampilan di peta tersebut menampilkan titik daerah wilayah yang terdampak bencana banjir. Titik yang ditampilkan sesuai dengan tingkat dampak yang diterima per wilayah kecamatan atau desa. Dengan titik yang berwana abu - abu berarti tidak terdampak, biru berarti rendah, kuning berarti sedang dan merah berarti tinggi. Selain menampilkan titik wilayahnya juga menampilkan keterangan data bencana di setiap titik wilayah. Tampilan halaman peta terdampak dapat dilihat pada Gambar 5.

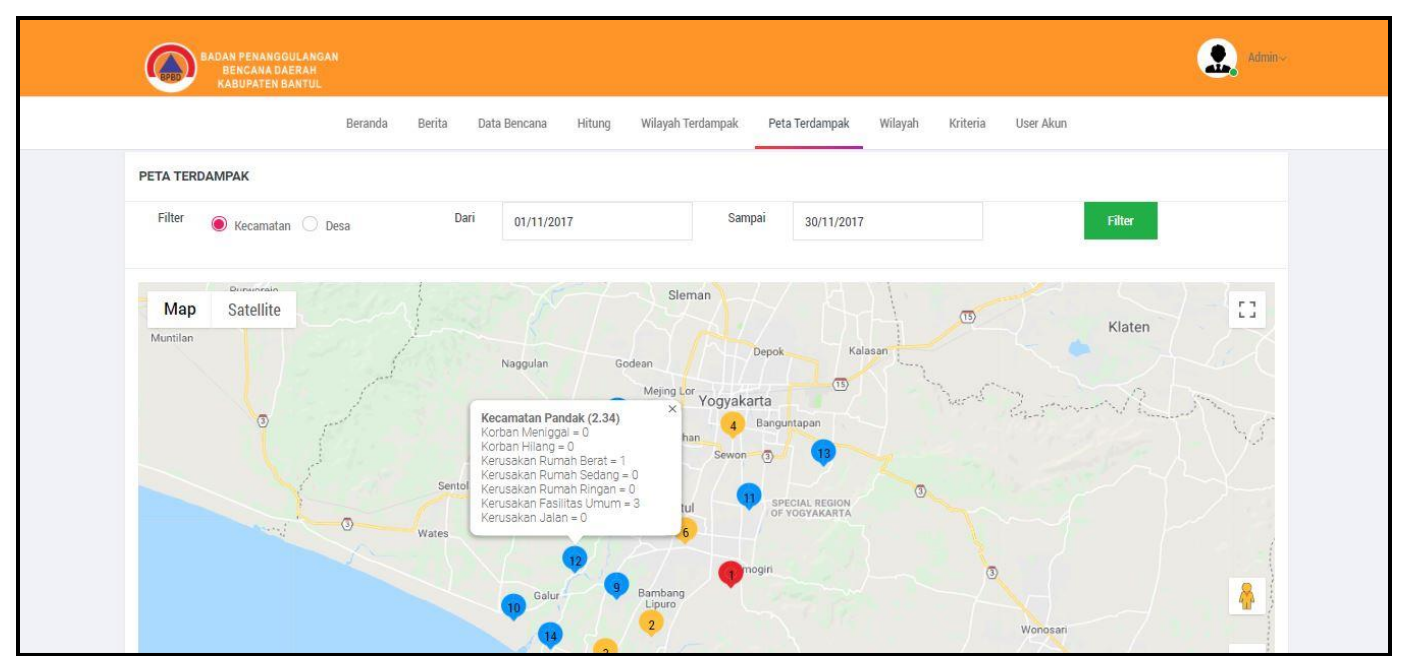

Gambar 5 Tampilan Peta Terdampak

\subsection{Pengujian sistem}

Data yang digunakan dalam penelitian ini merupakan Data Informasi Bencana Indonesia (DIBI) dimana data ini dikelola oleh pusdalops BPBD Kabupaten Bantul. Didalam data DIBI berisi data history dari kejadian bencana banjir di Kabupaten Bantul. Data tersebut yang 
digunakan dalam penelitian untuk menentukan tingkat dampak bencana banjir di Kabupaten Bantu khususnya data pada tahun2017.

Dari data DIBI yang sudah diproses menghasilkan nilai skoring yang bernilai 1 = Rendah, 2 = Sedang, 3 = Tinggi. Nilai skoring tersebut yang menentukan tingkat dampak bencana banjir di Kabupaten Bantul. Bencana yang terjadi pada tahun 2017 wilayah Kabupaten Bantul terdapat 9 wilayah desa yang tidak terdampak yaitu desa pleret, triwidadi, ringinharjo, wirokerten, panggungharjo dan lain sebagainya, 45 wilayah terdampak rendah yaitu desa wukisari, tamanan, singosaren, potorono, trimulyo dan lain sebagainya, 2 terdampak sedang yaitu desa selopamioro dan donotirto, dan 1 wilayah terdampak tinggi berada di desa sriharjo kecamatan imogiri. Dari hasil penelitian dapat ditampilkan hasil pemetaan dari sistem pemetaan tingkat dampak dapat dilihat pada Gambar 6.

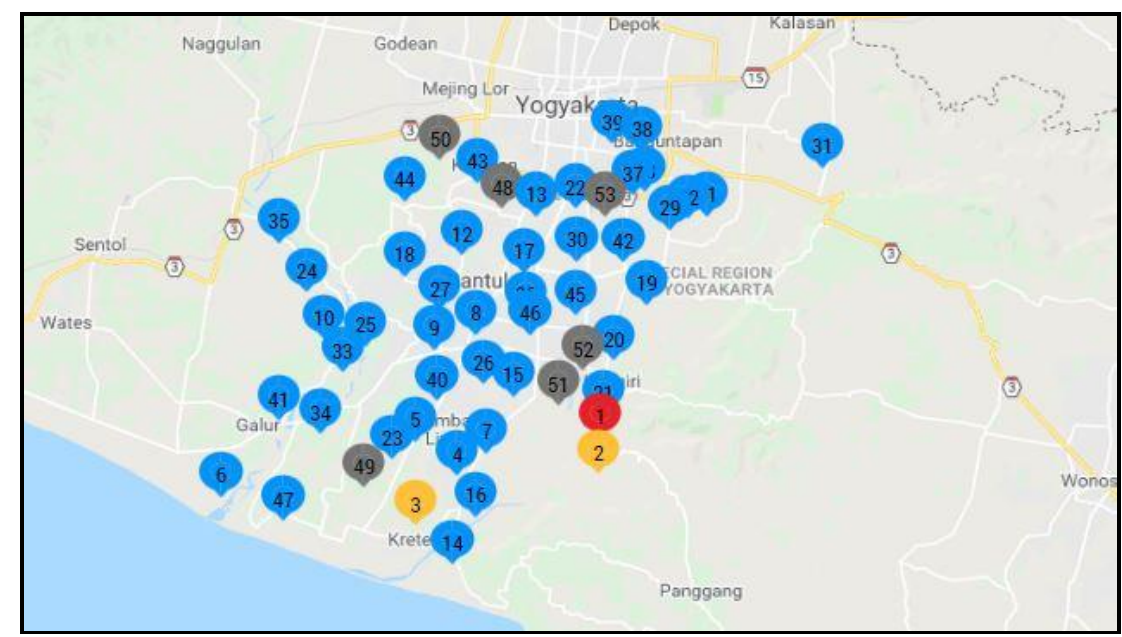

Gambar 6 Pemetaan Tingkat Dampak Pada Sistem

Gambar 6 merupakan gambar pemetaan tingkat dampak bencana banjir yang diperoleh dari hasil perhitungan skoring yang ditampilkan pada sistem. untuk mengetahui tingkat keakuratannya akan dibandingkan dengan hasil pemetaan tingkat dampak bencana banjir yang dilakukan oleh BPBD Kabupaten Bantul. Hasil pemetaan nya dapat dilihat pada Gambar 7.

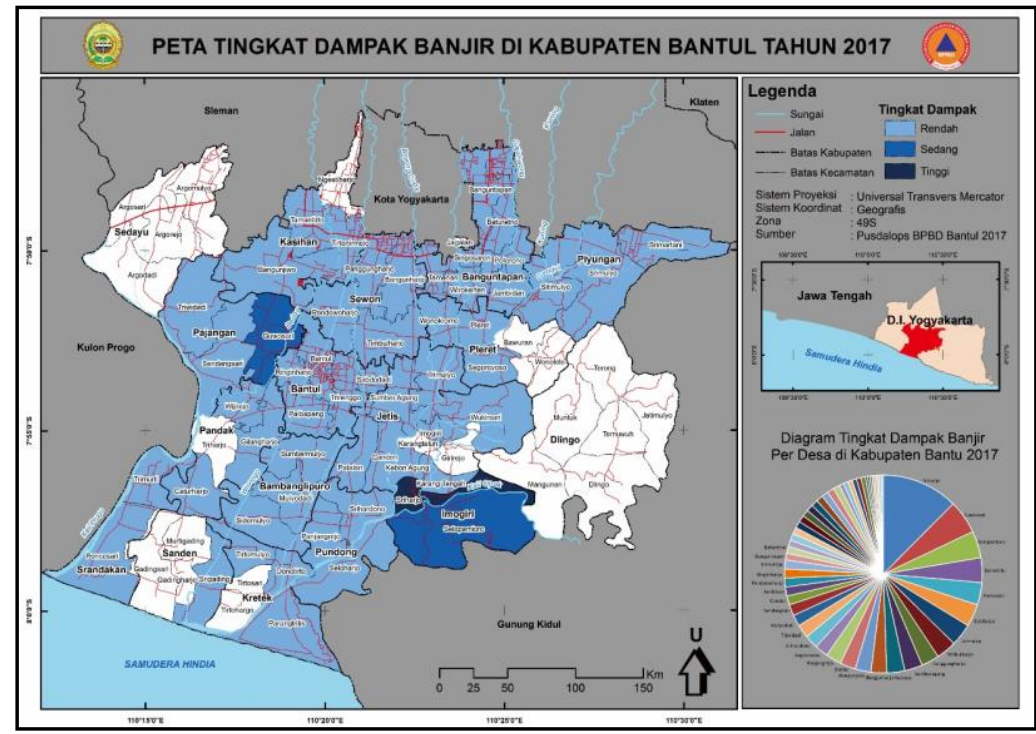

Gambar 7 Pemetaan Tingkat Dampak BPBD

Dari hasil pengujian sistem yang dilakukan BPBD Kabupaten Bantul dengan cara mencoba menjalankan sistem serta melakukan perbandingan hasil peta yang dihasilkan oleh sistem dan peta yang dihasilkan oleh BPBD. Memiliki hasil yang agak sedikit berbeda dikarenakan kriteria yang digunakan tidak semuanya dalam menentukan tingkat dampak bencana banjir, pada 
proses sistem hanya menggunakan 5 kriteria sedangkan BPBD Kabupaten Bantul menggunakan 20 kriteria. Sehingga dalam melakukan pemetaan tingkat dampak bencana banjir ini memiliki hasil persentase 95\% keakuratan yang dihasilkan dari sistem jika dibandingkan dengan pemetaan dari BPBD Kabupaten Bantul.

\section{PENUTUP}

\subsection{KESIMPULAN}

Dari hasil penelitian ini dapat diambil kesimpulan bahwa dari data pada tahun 2017 yaitu Data Informasi Bencana Indonesia (DIBI) yang digunakan untuk melakukan sebuah penelitian untuk menentukan daerah tingkat bencana banjir di Kabupaten Bantul pada wilayah desa memiliki hasil 9 wilayah desa yang tidak terdampak yaitu desa pleret, triwidadi, ringinharjo, wirokerten, panggungharjo dan lain sebagainya, 45 wilayah terdampak rendah yaitu desa wukisari, tamanan, singosaren, potorono, trimulyo dan lain sebagainya, 2 terdampak sedang yaitu desa selopamioro dan donotirto, dan 1 wilayah terdampak tinggi berada di desa sriharjo kecamatan imogiri.

Sedangkan untuk wilayah kecamatan memiliki hasil 3 wilayah tidak terdampak yaitu kecamatan Bantul, Pajangan dan pleret, 9 wilayah terdampak rendah yaitu Bantul, Bambang Lipuro, Srandakan dan lain sebagainya, 6 wilayah terdampak sedang yaitu kecamatan pundong, kretek, banguntapan, sewon dan lain sebagainya, 1 wilayah terdampak tinggi yaitu kecamatan imogri. Dari hasil pengujian sistem dan validasi sistem dapat diambil kesimpulan hasil pemetaan tingkat dampak yang dihasilkan dari sistem memiliki tingkat keakuratan $95 \%$ jika dibandingkan dengan hasil pemetaan yang dilakukan oleh BPBD Kabupaten Bantul dikarenakan data kriteria yang digunakan pada sistem tidak sama. Sehingga jika terjadi penambahan kriteria pada sistem ada kemungkinan akan terjadi perubahan pada hasil pemetaan atau hasil nilai perhitungannya.

\subsection{SARAN}

Pembuatan sistem pemetaan tingkat dampak bencana banjir di Kabupaten Bantul menggunakan metode Multi Attribute Utility Theory (MAUT), terdapat beberapa saran sebagai masukan agar dapat dilakukan pengembangan sistem selanjutnya, yaitu :

1. Dapat digunakan basis yang lainnya dalam mengembangkan sistem ini seperti menggunakan android, supaya lebih efisien dalam mengaksesnya.

2. Dalam melakukan perhitungan tingkat dampak bencana banjir dapat menggunakan metode pendukung keputusan yang lain supaya dapat dibandingkan tingkat keakuratannya.

3. Kriteria bencana dapat ditambahkan lagi selain kriteria korban meninggal, korban hilang, kerusakan rumah, kerusakan fasilitas umum, kerusakan jalan.

4. Dapat menampilkan grafik untuk mengetahui tingkat dampak bencana banjir di Kabupaten Bantul.

5. Tampilan peta terdampak dapat menggunakan selain google maps yaitu tampilan peta polygon.

\section{DAFTAR PUSTAKA}

Hidayat, M., \& Jusia, P. A. (2018). Analisa dan Perancangan Sistem Pendukung Keputusan Untuk Penerimaan Karyawan PT . Dos Ni Roha Jambi Menggunakan Metode MAUT ( Multi Attribute Utility Theory ), 13(1).

Imam Rofi'i, Hendrawan, Pareza Alam Jusia, 2015, Perancangan aplikasi e-ticketing pada PO.CV. Jambi Transport berbasis web, Processor Vol.10 No.2 Oktober 2015 ISSN 19076738.

Kodoatie, Robert J. \& Sugiyanto. 2002. "Banjir" Beberapa Penyebab dan Metode Pengendaliannya dalam Perspektif Lingkungan. Pustaka Pelajar :Yogyakarta.

Schaefer, 2012, Multi Attribute Utility Theory, http://digilib.tes.telkomuniversity.ac.id/metodemultiattribute-utility-theory-maut, diakses 29 Maret 2018.

Sugiyono. (2012). Metode Penelitian Kuantitatif Kualitatif dan R\&D. Bandung: Alfabeta. 